\title{
Acedapsone in the Preventive Treatment of Leprosy
}

\author{
D. A. RUSSELL \\ Department of Health, Papua-New Guinea \\ R. M. WORTH* \\ School of Public Health. University of Hawaii \\ B. JANO \\ Department of Health, Ponape, Micronesia \\ P. FASAL \\ Public Health Service Hospital, San Francisco, California, U.S.A. \\ C. C. SHEPARD \\ Public Health Service Center for Disease Control \\ Atlanta, Georgia, U.S.A.
}

Well designed and carefully executed trials of dapsone in the preventive treatment of children with household exposure to leprosy in India have shown only a partial success in reducing the subsequent incidence of leprosy among the children in the study (Nordeen, 1969; Wardekar, 1969). The difficulty of ensuring consistent dosage of oral medication over a period of 3 years may have been a factor in these results. When acedapsone [diacetyl-diamino-diphenyl sulphone (DADDS; Hansolar)] became available for experimental use in the late 1960's it then became possible to repeat the trial, with the certainty of a low, consistent blood level of DDS, through 5 intramuscular injections of acedapsone per year (Ozawa, Shepard and Karat, 1971).

\section{Methods}

The history of leprosy in this population and of our earlier work has been described elsewhere (Sloan et al., 1972). Leprosy had been first introduced into Pingelap in 1918 via an immigrant case from Nauru, and is known to have been at high prevalence in this population since at least 1950. In the autumn of 1967 the entire population (except for some 20 persons who were out of the district at the time) of approximately 1500 highly in-bred people of Pingelap atoll origin were examined for leprosy in three villages in the Ponape District of the Eastern Caroline Islands. This complete examination by one highly experienced leprologist, Dr Norman Sloan, plus a careful review of existing records, revealed a total of 99 cases of leprosy confirmed by biopsy, 62 of which were clinically

\footnotetext{
* Requests for reprints should be sent to Dr Worth.
} 
active in 1967. The remaining 37 were treated, inactive cases. The experience of this population during the 5-year period 1963 to 1967 inclusive led to an estimate of an incidence of about 11 new cases per year.

Beginning in October 1967. the entire population of these three villages, including the known cases of leprosy, were placed under the following DADDS treatment or preventive treatment programme:

Age 6 years or more: $1.5 \mathrm{ml}(225 \mathrm{mg})$ i.m. every 75 days

Age 6 months to 5 years: $1.0 \mathrm{ml}(150 \mathrm{mg})$ i.m. every 75 days

Age 0 to 5 months: if born before October 1968. started on DADDS at age 6 months; if born October 1968, or later, not started on DADDS.

Dr Sloan returned to Ponape each year in the autumn of 1968, 1969, and 1970 to re-examine the entire population, to take a biopsy specimen from all known cases, to follow the response to treatment, and to look for any new cases arising in the population. Any suspicious skin lesion was biopsied. Every time a person was given his DADDS he was questioned and given a superficial examination by a nurse for signs and symptoms of leprosy. This intensive surveillance continued until preventive treatment was halted in the autumn of 1970, but the diagnosed cases of leprosy continued under DADDS therapy Since that time. passive surveillance of this population has been continued by the personnel of the Ponape Health Department, supplemented by an annual leprosy examination given to each member of this population by an experienced leprologist. All biopsy specimens since 1967 have been examined by the same leprologist in San Francisco, and all mouse foot-pad inoculations have been performed in the same laboratory in Atlanta.

\section{Results}

Figure 1 is a summary of the results of the surveillance of this population from 1968 through January, 1973.

It is clear that after a 6-month lag period, during which incidence was unaffected, the level of DADDS used in this population was sufficient to suppress the clinical onset of new cases of leprosy. This effect lasted for 3 years, until about 6 months after the preventive treatment with DADDS was halted.

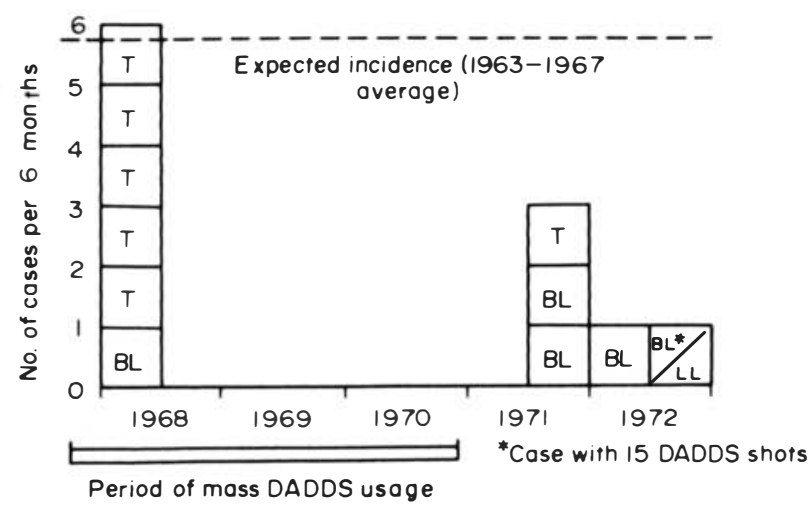

Fig. 1. Leprosy incidence among Pingelapese people, 1968-1972, by six-month interval and by histological types. 
TABLE I

Distrihution of $1.571^{\text {a }}$ Pingelapese people who were hoin hefore 1969 and who did not have leprosy at the end of 1970, hy history of IDADIDS preventive treatment and by subse(puent leprosy incidence

\begin{tabular}{|c|c|c|c|c|c|}
\hline \multirow[b]{2}{*}{ Status of population at risk } & \multicolumn{4}{|c|}{ No. of DADIDS shots during 1967-70 } & \multirow[b]{2}{*}{ Tota } \\
\hline & $0-3$ & $4-6$ & $7-13$ & $14-15$ & \\
\hline \multirow{5}{*}{$\begin{array}{l}\text { Alive at end of } 1970 \\
\text { Died } 1971-72 \\
\text { New cases } 1971-72 \\
\text { Without leprosy in January } 1973 \\
\text { Average annual leprosy incidence } \\
\quad 1971-72\end{array}$} & 234 & 173 & 241 & 923 & 1571 \\
\hline & -12 & -4 & -4 & -6 & -26 \\
\hline & -1 & -0 & -3 & -1 & -5 \\
\hline & 221 & 169 & 234 & 916 & $1540^{t}$ \\
\hline & \multicolumn{3}{|c|}{$3.1 / 1000$} & $0.5 / 1000$ & \\
\hline
\end{tabular}

$a$ There are 2.32 additional Pingelapese children horn during 1969-72, who have survived infancy, have received no DADI)S, and who have not yet produced any cases of leprosy.

${ }^{b}$ All but 40 of these people were examined in January 1973.

Table 1 is a distribution of the population at risk at the end of 1970 by the number of DADISS injections received, and shows the subsequent leprosy incidence; 4 of the new cases had received 10 or fewer injections of DADDS as preventive treatment. One of these persons developed tuberculoid leprosy, and the other 3 developed BL leprosy. The remaining new case is in a young boy who had received all 15 injections between the ages of 2 and 5 years and who developed BL-LL leprosy during the autumn of 1972 . He comes from a family containing several other leprosy patients.

Of the 56 cases with an onset between 1963 and 1967, classified as borderline or lepromatous leprosy. Of the 6 cases with an onset early in 1968, one (18\%) was BL in classification. Of the 5 cases with an onset after 1970 all but one have been classified as having BL or LL disease: the exception is the daughter of an old patient with lepromatous disease due to a proven sulphone-resistant strain of My'co. leprae.

Of the 68 cases that were clinically active in 1967-68, all are doing well on DADDS (the sulphone-resistant case is on B663), except for 6 whose disease has recently reactivated or undergone a $\mathrm{TT}$ to $\mathrm{BL}$ shift, associated with irregular therapy.

\section{Discussion}

If the appearance of new cases ceases in the next few years, then it is possible that all the cases appearing in 1971-72 represent infections that took place prior to 1968. and that we have managed to stop the transmission of all sulphone-sensitive strains of Myco. leprae in this population.

It seems probable from the data that have thus far been obtained that:

(1) Two or three injections of DADDS will not suppress the development of clinically recognizable leprosy in those who are about to develop it, but more than 2 or 3 injections will apparently suppress the development of further new cases in the population for the duration of the preventive treatment.

(2) There appears to be some, as yet, ill-defined threshold of DADDS injections (perhaps less than 15 injections) sufficient to prevent (or at least delay for several years) the onset of tuberculoid or indeterminate leprosy lesions in 
those who had been infected and whose immunological status is such that they would have developed these forms of leprosy.

(3) When a preventive treatment course of DADDS (15 injections) is stopped among those who had been infected and whose immunological status is such that they would have developed borderline or lepromatous leprosy, the incidence of these forms of leprosy will return from zero, but to a much lower rate than formerly. Among those who received less than a full course of DADDS, the incidence will return to a higher, but not yet clearly defined rate.

Several more years of careful surveillance of this population will be required to confirm the reliability of these observations, but if they are true, the implications for the successful use of DADDS preventive treatment are fairly clear:

(1) Fifteen injections of DADDS in heavily exposed groups (such as household contacts of infectious cases, etc.) can reduce the subsequent load of clinical cases of leprosy to a level far below what it would have been, but will not immediately lead to a break in the chain of transmission in that population, since new cases of infectious leprosy will continue to appear for several years, but at a rate considerably lower than before.

(2) Because of the reappearance of new infectious cases, a good control programme would have to include a careful surveillance of household contacts for several years after the end of their DADDS preventive treatment, a prompt and thorough treatment of any new infectious case that appears, and a re-institution of preventive treatment for all those who had been exposed to the new infectious case before this patient was placed under treatment (Worth and Wong, 1971).

(3) A leprosy control programme based on the above principles, with combined therapy of DADDS and one other drug in those "bacilliferous" cases with a bacillary index of $2+$ or more (Shepard, 1973) holds the possibility of a practical, economical, and fairly rapid eradication of leprosy in any population. This approach will be tested for the next few years in this Pingelapese population. and it should also be tested in other populations.

\section{Acknowledgement}

The work upon which this publication is based was performed pursuant to Contract No. NIH-NIAID-72-2075 with the U.S. National Institutes of Health, Department of Health, Washington, D.C., U.S.A.

\section{References}

Noordeen, S. K. (1969). Chemoprophylaxis in leprosy. Lepr. India 41, 247-254.

Wardekar, R. V. (1969). Chemoprophylaxis in leprosy. Lepr. India 41, 240-246.

Ozawa, T., Shepard, C. C. and Karat, A. B. A. (1971). The application of spectrofluorometric procedures to some problems in Mycohacterium leprae infections in mice and men treated with diacetyl-DDS (DADDS) and diformyl-DDS (DFD). Am. J. Trop. Med. Hyg. 20, 274-281.

Sloan, N. R., Worth, R. M., Jano, B., Fasal, P. and Shepard, C. C. (1972). Acedapsone in leprosy treatment: trial in 68 active cases in Micronesia. Int. J. L.epr. 40, 48-52;

Sloan, N. R., Worth, R. M., Jano, B., Fasal, P. and Shepard, C. C. (1972). Acedapsone in leprosy chemoprophylaxis, Field trial in three high-prevalence villages in Micronesia. Int. J. Lepr. 40, 40-47.

Worth, R. M. and Wong, K. O. (1971). Further notes on the incidence of leprosy in Hong Kong children living with a lepromatous parent. Int. J. Leprosy' 39, 744-748.

Shepard, C. C. (1973). Personal communication. 